\title{
LOW POWER PH SENSOR FOR - WIRELESS SENSOR NeTWORK NODE Agricultural APPLiCATiON
}

\author{
Kshitij Shinghal $^{1}$, Arti Noor ${ }^{2}$, Neelam Srivastava ${ }^{3}$, Raghuvir Singh $^{4}$ \\ ${ }^{1}$ Department of E\&C Engg., Moradabad Institute of Technology, Moradabad, India. \\ ${ }^{2}$ Department of M. Tech. VLSI Design Group, C-DAC, Noida, India. \\ ${ }^{3}$ Department of E\&C Engg., Institute of Engineering \& Technology, Lucknow, India. \\ ${ }^{4}$ Shobhit Institute of Engineering and Technology, Gangoh (SIET), India.
}

\begin{abstract}
A Wireless Sensor Networks (WSN) is now widely used in precision agriculture applications. Sensors play an important role in WSN. The measurement of soil $\mathrm{pH}$ is arguably the most widely performed test in the chemical laboratory, the use of $\mathrm{pH}$ sensitive field-effect transistors (pHFETS) is proposed for remote monitoring of the nutrient solution composition for an agricultural farm soil. The proposed system was formed by a sensor system based on polymeric (PVC) membranes with cross selectivity with time triggered sampling of sensor and its signal conditioning. With the optimized model, th0e pH levels of soil were monitored and the time triggered approach for sampling sensor improved the performance and lifetime of WSN node. The approach appears as a feasible method for the on-line assessment of nutrients and undesired compounds in fertigation solutions.
\end{abstract}

KEYWORDS: WSN, pHFET, Ph Sensors, Low Power WSN, Power Management.

\section{INTRODUCTION}

A wireless sensor network is a system comprised of radio frequency (RF) transceivers, sensors, microcontrollers and power sources. Wireless sensor networks with self-organizing, self-configuring, self-diagnosing and self-healing capabilities have been developed to solve problems or to enable applications that traditional technologies could not address. Once available, these technologies would allow us to find many new applications that could not have been considered possible before.

\section{WHY WIRELESS SENSORS?}

An obvious advantage of wireless transmission is a significant reduction and simplification in wiring and harness. Wireless sensors allow otherwise impossible sensor applications, such as monitoring dangerous, hazardous, unwired or remote areas and locations. This technology provides nearly unlimited installation flexibility for sensors and increased network robustness. Furthermore, wireless technology reduces maintenance complexity and costs $[1,2]$.

\section{APPLICATIONS OF WIRELESS SENSORS AND NETWORKS IN AGRICULTURE AND FOOD PRODUCTION}

Modern agriculture offers a range of benefits, including greater production and higher incomes for farmers including small producers in both developed and developing countries. Technical advances also have sharply reduced environmental impacts, enabling reduced pesticide, herbicide and fertilizer use, less tillage, and less land and water use per unit of output all decreasing pressure on fragile global ecosystems[10]. It is clear that we have a productivity gap going forward, a gap that we must begin now to close. If we are to double agricultural output by 2050 and do so with basically the same amount of land and water as we have today while also reducing the environmental footprint then clearly we must become more productive than we have been in the past. That is the productivity gap, which is our challenge [3, 4]. 
Recently, potentiometric sensors have appeared that take profit of the electric field generated by the membrane potential caused by presence of specific ions; the electric field modulates current in a field effect transistor, in this way these sensors are known as Ion Selective Field Effect Transistors (ISFETs). ISFET sensors have a great future in continuous monitoring, given that they are able to determine ions at very low concentrations and they can be massively produced using VLSI technology. In agricultural farms where operation and environmental conditions are quite aggressive the robust and cheap ionic sensors that provide real-time information of the ionic composition of the nutrient solution are very useful, although accuracy is not excessively high [10, 24].

The technique is also suitable for expensive crops like strawberry and mushrooms in closed soilless systems. The closed soilless systems is a techniques implemented in modern horticulture in order to improve the efficiency in the use of water and fertilizers and to preserve the environment. In few words, in this technique, plants grow on artificial substrates which substitute natural soil $[5,6]$. A fertilizer supply unit provides nutrients and the solution not used by the plants is collected and regenerated to be reused several cycles. The addition of new fertilizer ions (ammonium, potassium, nitrate, phosphate) and tap water is controlled by the value of electrical conductivity (EC) and $\mathrm{pH}$ signals. However, this protocol can only give a qualitative control over these species given ion's uptake by the plants may vary [7]. In the closed soilless systems non-essential ions such as sodium and chloride accumulate in nutrient solution causing an increase in the overall EC and consequently a decrease of the concentration of the nutrient ions if the conductivity is maintained at a fixed value [8]. Therefore, the measurement of the concentration of each individual ion in the nutrient solution in continuous mode, and in real-time can be a clear improvement to normal use in this area, and can lead to fine control of fertilizer dosage adapted to each plant stage $[9,10,11]$.

\section{HARDWARE AND SOFTWARE REQUIREMENTS FOR WIRELESS SENSORS}

Hardware requirements for wireless sensors include: (1) robust radio technology, (2) low cost, energyefficient processor, (3) flexible I/O for various sensors, (4) long-lifetime energy source and (5) flexible, open source development platform. Various types of WSN nodes which are integrated processor-radio units have been developed to satisfy these requirements. Software requirements for wireless sensors include: (1) small footprint to run on small processors, (2) efficient energy use, (3) capability of fine grained concurrency, (4) high modularity and (5) robust ad hoc mesh networking that requires low power $[18,19]$.

\section{SYSTEM DESIGN AND ARCHITECTURE}

Detailed discussions of proposed design and elements of the architecture for the system are presented below.

\section{A. The Sensing Element}

The ion-selective field - effect transistor (ISFETs) is used as the sensing element for $\mathrm{pH}$ measurement. ISFETs, of which the hydrogen ion sensitive pHFET is one variant, are derived from the metal-oxide-semiconductor FET (MOSFET). These silicon "chips" combine a $\mathrm{pH}-$ responsive membrane much like that of the glass electrode with the amplification of a fieldeffect transistor. The integral amplification and small size have led to the development of inexpensive, battery-powered, pocket-sized $\mathrm{pH}$ measurement systems. These devices have found unique and expanding applications, including the food industry where the measurement of $\mathrm{pH}$ using breakable glass electrodes presents an unacceptable safety hazard, the measurement of the $\mathrm{pH}$ of gels, pastes, and slurries, and for the measurement of strongly alkaline solutions where conventional glass bulbs respond to the sodium ions and give an erroneously low reading[20,21].

A schematic cross-section of a $\mathrm{pH}$-sensitive ISFET is presented in figure1. The pHFET differs from a MOSFET in that the metal gate of the MOSFET is replaced by a $\mathrm{pH}$ responsive membrane material such as silicon nitride, aluminum oxide, or tantalum oxide, 
which contacts the sample solution directly. As with the glass electrode, electrical contact is made to the sample through a reversible reference electrode. A suitable voltage applied to the reference electrode (relative to the silicon substrate) will charge the capacitor formed by the solution, insulating layers, and silicon substrate, and create mobile charge in the channel region. A potential simultaneously applied between the drain and source electrodes will result in current flow. Using a "charge imaging" model, this drain current, ids, can be described by equation 1:

$$
i_{d s}=A V_{d s} Q_{c}=A V_{d s} C_{2}\left[V_{g}-V_{T}-\frac{V_{d s}}{2}\right]
$$

Where the constant ' $A$ ' includes geometrical factors, Vds is the voltage applied to the drain, and $\mathrm{Q}_{\mathrm{c}}$ is the mobile channel charge. The mobile charge is a function of $\mathrm{Vg}$, the voltage applied to the reference electrode is $\mathrm{V}_{\mathrm{T}}$, the "threshold voltage" needed to produce mobile charge, and $\mathrm{C}_{2}$, the capacitance of the gate region. The threshold voltage includes a number of terms, one of which is the phase-boundary potential at the interface between the sample and the $\mathrm{pH}$-responsive insulating layer. Adsorption of protons at the surface of this layer leads to a Nernstian dependence of this potential on hydrogen ion activity with the result being that changes in $\mathrm{pH}$ modulate the drain current of the device [12, 13, and 14].

$$
i_{d s}=A V_{d s} C_{2}\left[V_{g}-V_{T}+2.3 \frac{R T}{F} p H-\frac{V_{d s}}{2}\right] \ldots \ldots
$$

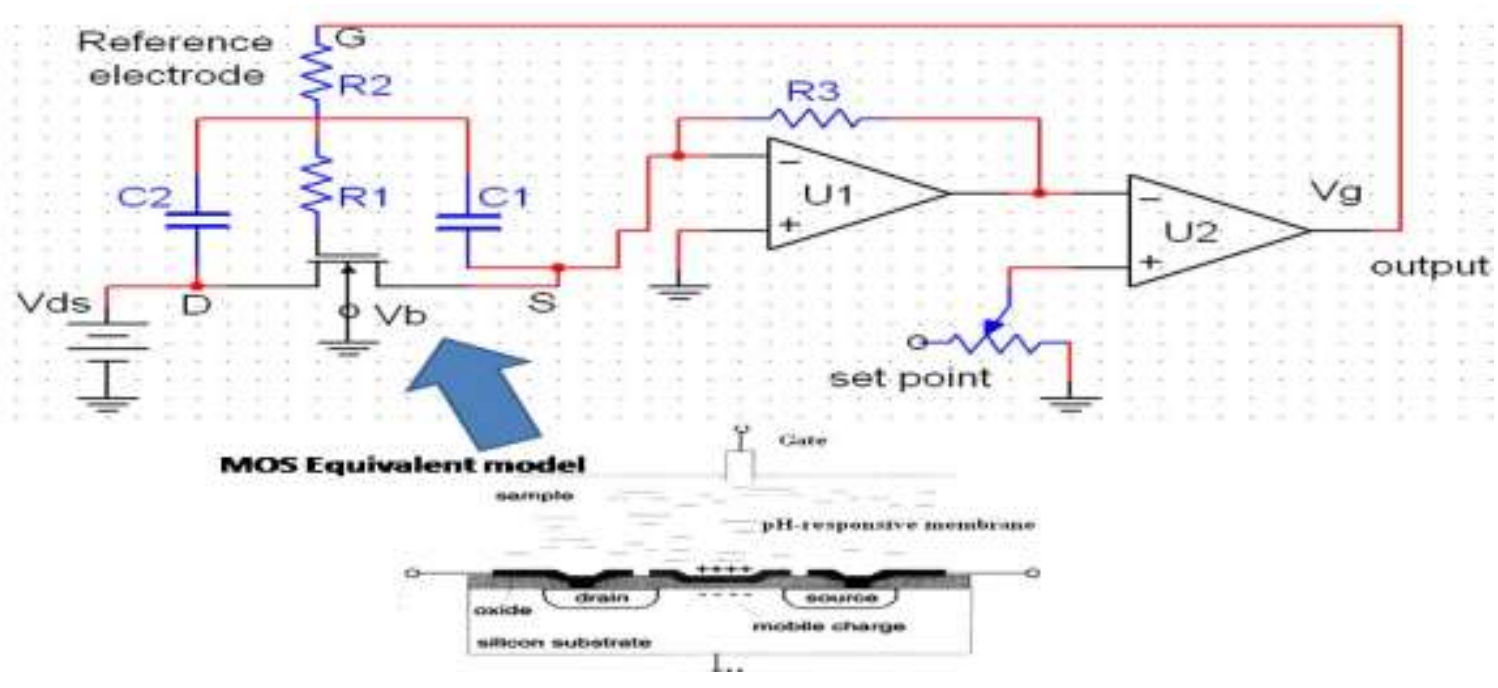

Figure 1 pH-measurement using an ion - selective field effect transistor, including signal conditioning for sensor

Equation 2 illustrates the dependence of ISFET current on $\mathrm{pH}$. The preferred method of operation of the pHFET is to operate at a constant drain current. A circuit for doing this is illustrated schematically in Figure 1. A transconductance amplifier converts the drain current to a voltage, which is referenced against a set point. The output of the comparator drives the reference electrode, Vg. Since the mobile channel charge $\mathrm{Q}_{\mathrm{c}}$ is constant, as are $\mathrm{V}_{\mathrm{ds}}$ and $\mathrm{V}_{\mathrm{T}}$, changes in the comparator output directly reflect changes in the hydrogen ion activity. That is, a $59-\mathrm{mV}$ change in output corresponds to a change in $\mathrm{pH}$ of one unit. Interface circuitry similar to that of Figure 1 allows the device to be connected directly to a glass electrode $\mathrm{pH}$ meter.

\section{B. Power management}

Power reduction strategies for the sensor include:

1. Turn power on to sensor only when sampling. 
2. Turn power on to signal conditioning only when sampling sensor.

3. Only sample sensor when an event occurs.

4. Lower sensor sample rate to the minimum required by the application.

In this paper the first and second techniques described above are applied for optimizing the power consumed i.e. to turn power ON to sensor only when sampling the data. In the proposed approach the sensor in the WSN node is not active for all the time but it is triggered on at regular intervals by the microcontroller. The microcontroller sends the signal to turn on the sensor for sampling and also subsequently power to the signal conditioning block of the sensor. Thereby significantly reducing the overall power consumption in comparison to the technique where the senor is active with its signal conditioning block for complete time.

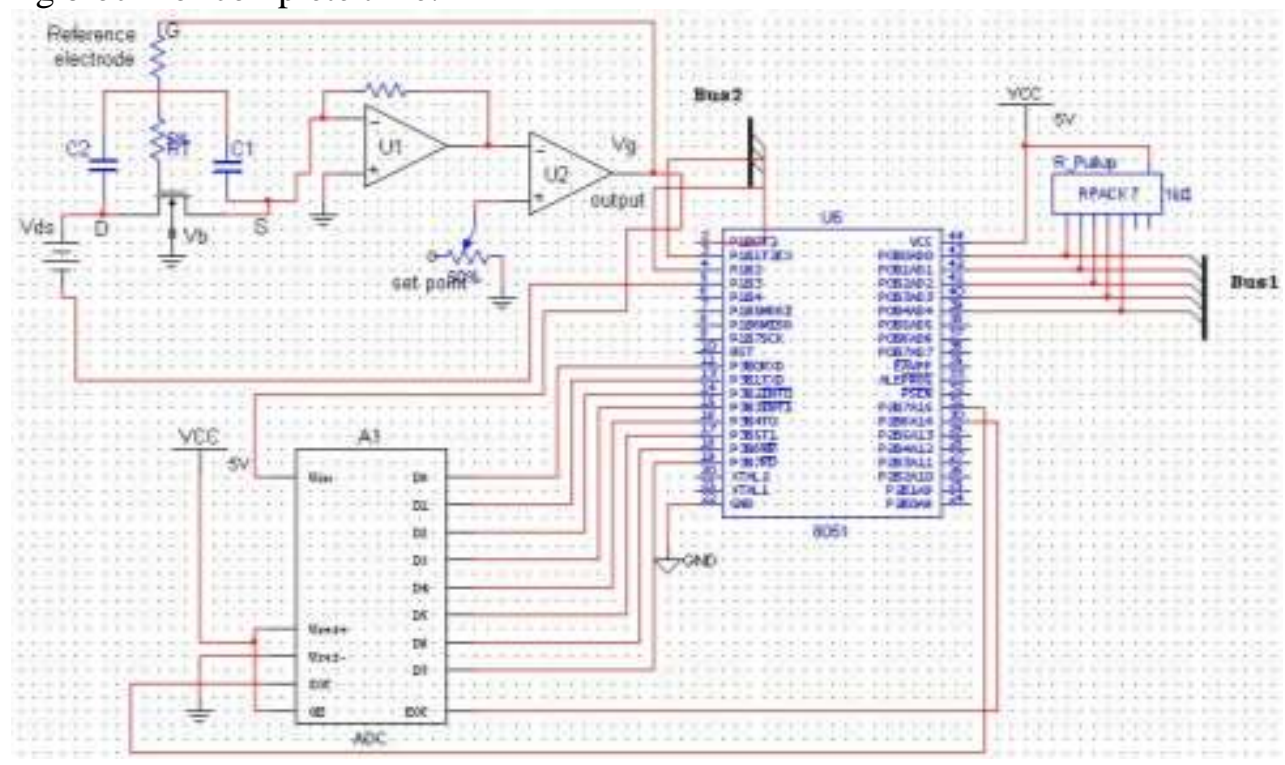

Figure 2 Circuit schematic of pH sensor with computational unit

\section{Computational Element}

Computational element used here is an application specific processor which can be later custom designed for the application. Here to perform the computational task a microcontroller 8051 is used. The microcontroller has several important tasks. First of all, it controls the sensor interface. It provides the settings of the sensor interface, such as the configuration of the sensor sampling intervals, the application mode. Secondly, it controls the power to the signal conditioning block of the sensor it turn power on to signal conditioning only when sampling sensor. Furthermore, it gathers the data coming from the sensor interface chip and stores it in a memory. The figure 2 shows the circuit schematic of $\mathrm{pH}$ sensor with microcontroller as a computational unit.

The microcontroller was programmed and incorporated in the circuit using co-simulation feature of NI Multisim -Multi MCU module [22]. A reference table was prepared and stored in the memory of the microcontroller. The microcontroller sends the sampling interval signal to the sensor from reference look up table stored in the memory. Further look up table can be updated dynamically for calibration of node by acquiring data from the Honeywell Honeywell Durafet III series $\mathrm{pH}$ sensor and can be compared with recently acquired data, changing the sampling interval in the look up table as per the requirement in days, nights or particular season [22].

\section{RELATED WORK}

There are numerous antecedents in the literature for the use of on-line sensors for monitoring and managing crops without soil but in practice, farmers have not been provided with ion sensors that are both economic and robust[3,7]. On the contrary, ionic sensors available have been expensive in relation to its lifetime and have sensitivity problems towards temperature and interfering ions as mentioned above. A novel strategy to solve these problems is the WSN nodes and remote sensing. This novel concept entails the use of an array of WSN nodes with partially selective response plus a multivariate calibration model to develop qualitative (identification) or quantitative (multi- 
determination) applications in soil $[13,14]$. Basically, this proposal represents an alternative to the ideal sensor with a very high selectivity, moving the complexity of the system to the data processing stage. Among the different types of sensors that can be used in a WSN node, potentiometric electrodes require relatively simple measuring devices and provide wide variety of sensing elements. An advantage of using WSN nodes with pHFET is that this allows us not only to obtain the concentration of the primary ion, but also the concentration of the interfering ions without the need of eliminating them. Further the time triggered sampling of the sensor reduces the overall power consumption of the WSN node [24].

\section{SIMULATION FRAMEWORK}

MULTISIM, manufactured by National Instruments, is a program conceived for the simulation of circuits that allow users to simulate circuit components, simultaneously with SPICE models and microcontrollers. The pHFET sensor for $\mathrm{pH}$ measurement described in this paper is modeled using ISFET model for VLSI, is based on a SPICE model the validation of the model is being performed on basis of SPICE simulations, with use of MULTISIM program [21, 23, 15]. First we will use MULTIMCU program for writing and checking the microcontroller code for the ISFET Sensor for ph measurement. Then the code will be optimized for time triggered sampling of the sensor.

\section{RESULTS AND DISCUSSION}

The calibration of $\mathrm{pH}$ sensor was realized according to the reference data obtained for Honeywell Durafet III series $\mathrm{pH}$ sensor which works with an accuracy better than $1 \%$. The calibration was done using National instruments Multisim software and then results were plotted. Figure 3, $4 \& 5$ shows the graphs drawn on the basis of output data obtained by various simulation tests conducted using NI Multisim[15].

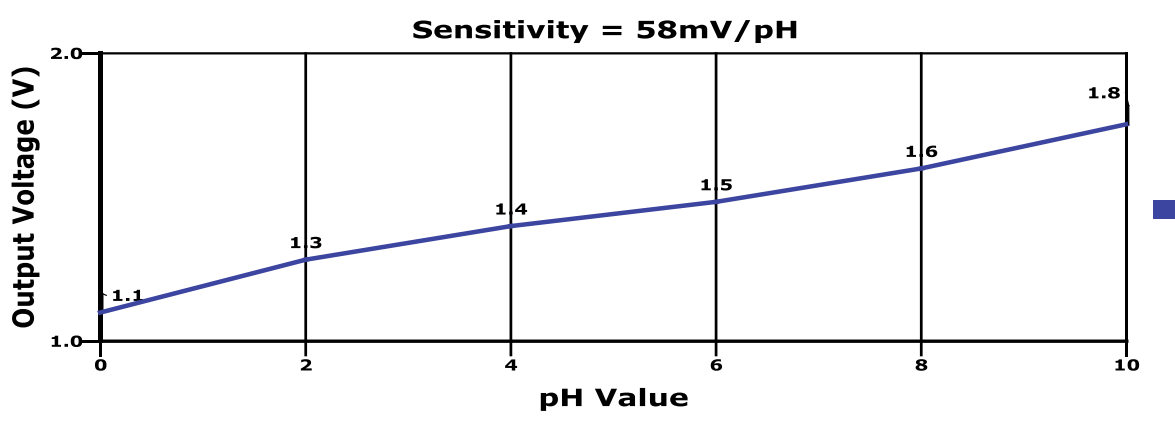

Figure 3 Plot of the output voltage vs. $p H$ values

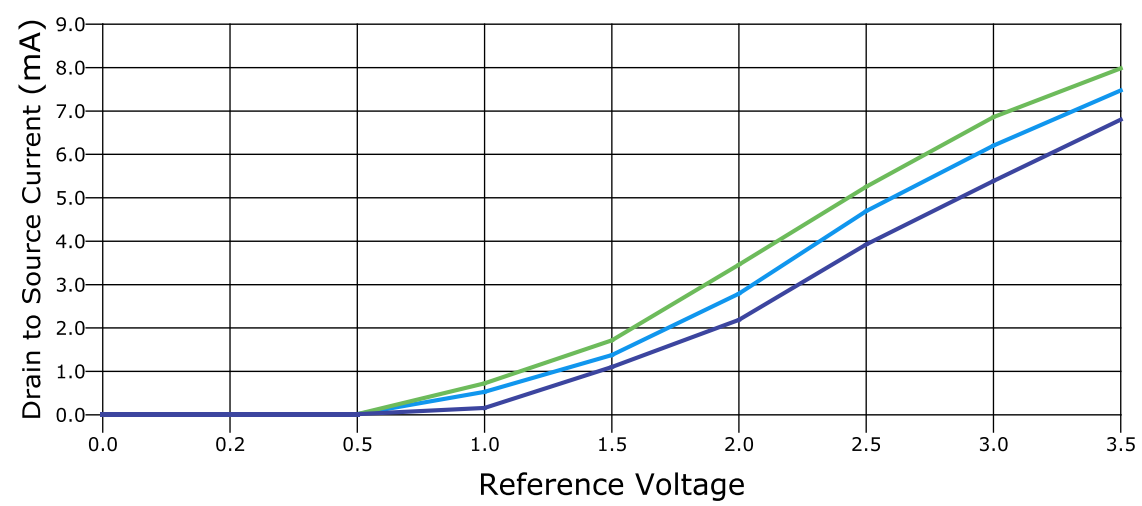

Figure 4 Drain current vs. reference voltage

- There was nearly linear drain current variation at the output interpreted from ISFET based PH sensor. 
- This variation in Current was converted in to voltage and there was almost linear relationship between the output voltage and PH.

- There is significant increase in performance for time triggered sampling in comparison with continuous sampling in terms of power consumption of the sensor since microcontroller activates the sensor and its signal conditioning unit only in the case of significant change in the $\mathrm{PH}$.

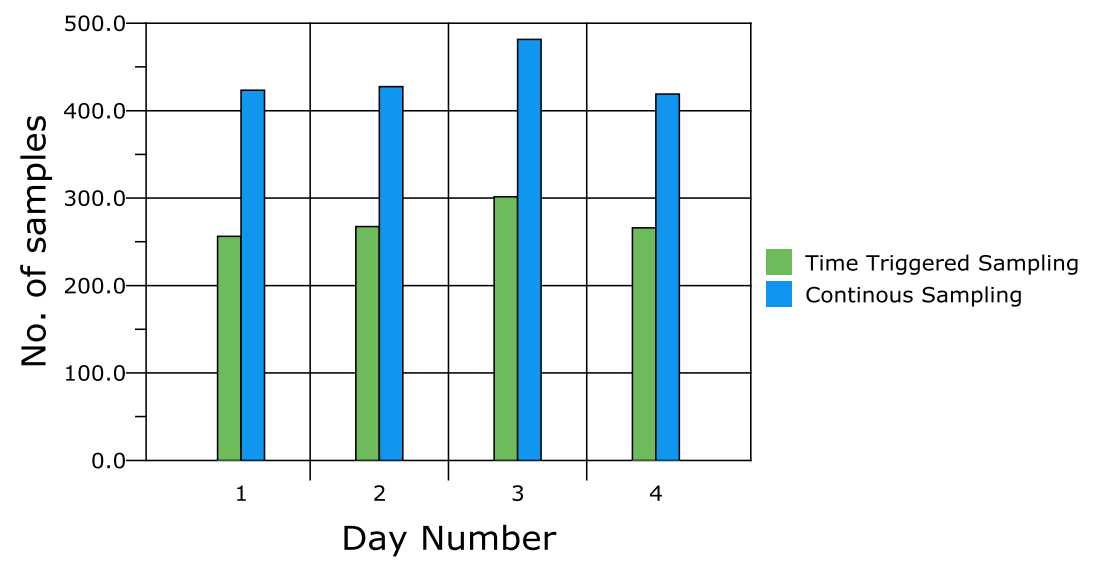

Figure 5 Comparison of time triggered Sampling vs. continuous sampling

\section{CONCLUSION}

A potentiometric WSN node for the simultaneous determination of ammonium, potassium, sodium, chloride and nitrate in greenhouse samples with fertigation strategy was simulated and optimized. The simulation results showed that the ISFET can be efficiently used for measuring $\mathrm{pH}[21,23]$. These results are very promising, given the intrinsic difficulty of the studied case. Ongoing simulations are focused to study the effect of sampling deadline misses due to time triggered sampling of sensor and how to correct its possible distortions. One alternative to correct this effect would be to flexible time triggering or event based triggering. So we can conclude that proposed system type can be a promising tool for automatic wireless chemical monitoring in Agricultural applications. With a tool like this a very precise control of the dosing of nutrient species may be attained, a goal in advanced use of fertilizers.

\section{REFERENCES}

[1] IEEE 1451.2 Standard, A Smart Transducer Interface for Sensors and Actuators. Transducer to Microprocessor Communication Protocols and Transducer Electronic Data Sheet (TEDS) Formats, Piscataway, NJ: IEEE Standards Department, 1998.

[2] Sensor Device Data/Handbook, DL200/D Rev. 4, 1998, Motorola Semiconductor Products Sector, Austin, TX.Najafi, K., .Smart Sensors,. J. Micromechanics and Microengineering, Vol. 1, 1991, pp. 86.102.

[3] Ina, O., .Recent Intelligent Sensor Technology in Japan,. Soc. Automotive Engineers, SAE891709, 1989.

[4] Maitan, J., .Overview of the Emerging Control and Communication Algorithms Suitable for Embedding Into Smart Sensors,. Proc. Sensors Expo, Cleveland, Sept. 20.22, 1994, pp. 485-500.

[5] E. J. Connoly, H. T. M. Pham , J. Groeneweg, P. M. Sarro and P. J. French "Relative humidity sensors using porous SiC membrane and Al electrodes," Sens. Actuators B, Chem., vol. 100, pp. 216, Jun. 2004.

[6] Installation Instructions for the HCH-1000 Series Capacitive Humidity Sensors ISSUE 150018326

[7] S. B. Crary, W. G. Baer, J. C. Cowles, and K. D. Wise, "Digital compensation of high-performance silicon pressure transducers", Sensors and Actuators A, 21-23:70-72, 1990.

[8] N. Yazdi, A. Mason, K. Najafi, and K. D.Wise, "A generic interface chip for capacitive sensors in lowpower multi-parameter microsystems", Sensors and Actuators A, 84:351-361, 2000.

[9] N. Yazdi, H. Kulah, and K. Najafi, "Precision readout circuits for capacitive microaccelerometers", In Proceedings IEEE Sensors Conference, pages 28-31, 2004. 
[10] Aline Baggio "Wireless sensor networks in precision agriculture"The Netherlands IEEE Pervasive Computing, 3(1):38-45, Jan-Mar 2004.

[11] P. M. Faia , C. S. Futado and A. J. Ferreira "Humidity sensing properties of a thick-film titania prepared by a slow spinning process," Sens. Actuators B, Chem., vol. 101, pp. 190, Jun. 2004.

[12] E. J. Connoly , G. M. O"Halloran , H. T. M. Pham , P. M. Sarro and P. J. French "Comparison of porous silicon, porous polysilicon and porous silicon carbide as materials for humidity sensing applications," Sens. Actuators A, Phys., vol. 99, pp. 25, Apr. 2002.

[13] A.Salehi , A. Nikfarjam and D.-J. Kalantari "Pd/porous-GaAs Schottky contact for hydrogen sensing applications," Sens. Actuators B, Chem., vol. 113, pp. 419, Jan. 2006.

[14] B. S. Kang , S. Kim , F. Ren , B. P. Gila , C. R. Abernathy and S. J. Pearton "Comparison of MOS and Schottky W/Pt-GaN diodes for hydrogen detection," Sens. Actuators B, Chem., vol. 104, pp. 232, Jan. 2005.

[15] NI Multisim user manualTM, "Analog Devices Edition: Getting Started with NI Multisim Analog Devices Edition”, available online. http://www.ni.com/pdf/manuals/372330a.pdf

[16] Ramon PallaÁs-Areny, John G. Webster, "Sensors and signal conditioning", A Wiley-Interscience publication, 2000.

[17] Creed Huddleston, "Intelligent Sensor Design Using the Microchip dsPIC®”, Elsevier Inc., 2007. [18] Jon S. Wilson, “Sensor Technology Handbook”, Elsevier Inc. 2005

[19] Hon Sum Wang, Marvin H.White, "A CMOS -Integrated ISFET Operational Amplifier Chemical Sensor Employing Differential Sensing”, IEEE transaction on Electronic Devices, Vol.36 No.3 pp.479-487, 1989

[20] Carlos Galup-Montoro and Marcio Cherem Schneider "Mosfet Modeling for Circuit Analysis And Design", World Scientific Publishing Co. Pte. Ltd., 2007

[21] Narain Arora, "Mosfet Modeling for VLSI Simulation”, World Scientific Publishing Co. Pte. Ltd., 2007

[22] Durafet II and Meredian II Combination pH/ORP Electrodes for Honeywell 7777 Mountings, Industrial Automation and Control, 16404 N. Black Canyon Highway, Phoenix, AZ 85023, (C Copyright 1996 Honeywell Inc.

[23] A.B.Bhattacharyya, "Compact Mosfet Models for VLSI Design”, John Wiley \& Sons (Asia) Pte Ltd, 2009

[24] Farkas, I., "Modelling and control in agricultural processes.", Comput. Electron. Agric.vol.49, pp.315-316, 2005

\section{Authors Biographies}

Kshitij Shinghal has 11 Years of experience in the field of Academic and is actively involved in research \& development activities. He obtained his Masters degree (Digital Communication) in 2006 from UPTU, Lucknow. He started his career from MIT, Moradabad. Presently he is working as an Associate Professor \& Head, Deptt of E\&C Engg., at MIT Moradabad. He has published number of papers in national journals, conferences and seminars. He has guided two Masters, more than sixty students of B. Tech, and guiding three M. Tech. theses. He is an active Member of Various Professional Societies such as ISTE, IACSIT, IAENG etc.

Arti Noor has 17 Years of R\&D experience in the field of VLSI design \& technology characterization, VHDL \& computer programming, and speech synthesis. She obtained her Ph.D. (Electronics and communication Engineering) in 1990 from Banaras Hindu University, Banaras. She started her career from CEERI, Pilani and then joined the CDAC, Noida as Scientist EI. Presently she is working as an Associate Professor (Scientist-E) \& HoD, M. Tech VLSI Division at CDAC Noida. She was also involved in various research development activities in CEERI, Pilani and in CDAC, Noida. She worked on many consultancy projects for ISRO Bangalore, IIT Delhi, ISAC Bangalore, and VSSC Trivandram. She has guided Two Ph.D in the area of Microelectronics and VLSI Design, 50 students of B.Tech/M.Sc./ M. Tech/ ME, more than 15 M.Tech. theses.

Neelam Srivastava has 22 Years of experience in the field of Wireless Sensor Network design. She obtained her Ph.D. (Electronics and communication Engineering) in 2004 from Lucknow University, Lucknow. She started her career from IET, Lucknow. Presently she is working as an Associate Professor, Deptt of E\&C Engg., at IET Lucknow. She is involved in various research \& development activities. She is guiding two Ph.D. in the area of Wireless Sensor Networks, 50 students of B. Tech, more than $15 \mathrm{M}$. Tech. theses.

Raghuvir Singh has experience in Research, Development, Teaching and Administration for more than 40 years. He obtained his B.Sc., B.E. (Telecommunication), M.E. (Electronics) and Ph.D. (Electronics and communication Engineering) Degrees in 1958, 1962 \& 1970 respectively. He worked in CEERI, Pilani and retired as Head of Electronics \& Communication Engineering Department of University of Roorkee (presently IIT Roorkee). He was awarded the IETE award in 1965, Khosla Research Award in 1970 and Anna University National Award for his outstanding career and contribution to Engineering and Technology in 1994.His name was recommended by IETE Award Committee for the FICCI Award in 1999. He has supervised 5 Ph.D. theses, 45 M.E. dissertations and has more than 50 publications in National and International Journals and conferences to his credit.
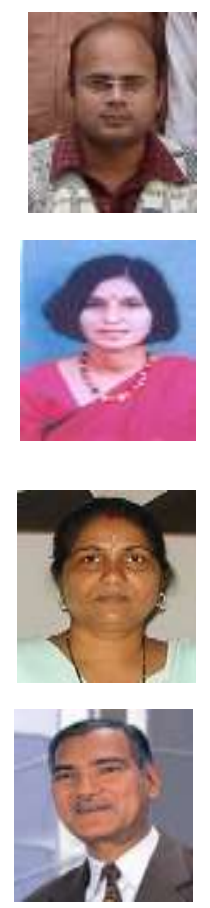